\title{
RECENT DEVELOPMENTS IN InGaN-BASED BLUE LEDS AND LDS
}

\author{
S. NAKAMURA* \\ Department of Research and Development, Nichia Chemical Industries, Ltd. \\ 491 Oka, Kaminaka, Anan, Tokushima 774, Japan
}

\begin{abstract}
$\mathrm{UV} / \mathrm{blue} /$ green/amber InGaN quantum-well structure light-emitting diodes with an external quantum efficiency of $7.5 \%, 11.2 \%, 11.6 \%$, and $3.3 \%$ were developed. The localization in the In $\mathrm{GaN}$ well layer induced by the In composition fluctuations seems to be a key role of the high efficiency of those In GaN-based light-emitting diodes. When the electrons and holes are injected into the In GaN active layer of the light-emitting diodes, these carriers are captured by the localized energy states before they are captured by the nonradiative recombination centers caused by the large number of threading dislocations. InGaN multi-quantum-well structure laser diodes with modulation doped strained-layer superlattice cladding layers grown on the epitaxially lateral overgrown GaN substrate were demonstrated to have an estimated lifetime of more than 10000 hours under-room temperature continuous-wave operation. When the laser diode was formed on the GaN layer above the $\mathrm{SiO}_{2}$ mask region without any threading dislodations, the threshold current density was as low as $2.7 \mathrm{kA} \mathrm{cm}^{-2}$. When the laser diode was formed on the window region with the high threading dislocation density, the threshold current density was as high as 4.5 to $9 \mathrm{kA} \mathrm{cm}^{-2}$. A leakage current due to a large number of threading dislocations caused the high threshold current density on the window region.
\end{abstract}

PACS numbers: $68.55 . \mathrm{Ce}, 72.80 . \mathrm{Ey}, 73.60 . \mathrm{Br}, 71.55 . \mathrm{Eq}$

\section{Introduction}

The brightness and durability of light-emitting diodes (LEDs) makes them ideal for displays, while semiconductor laser diodes (LDs) have been used in everything from optical communications systems to compact disk players. These applications have been limited, however, by the lack of materials that can emit blue light efficiently. Full-color displays, for example, require at least three primary colors, usually red, green and blue, to produce any visible color. Such a combination is also needed to make a white-light emitting device that would be more durable and less power consumption than conventional incandescent bulbs or fluorescent

${ }^{*}$ tel: +81-884-23-7787, fax: +81-884-23-1802, e-mail: shuji@nichia.co.jp 
lamps. The shorter wavelength means that the light can be focused more sharply, which would increase the storage capacity of magnetic and optical disks. Digital versatile disks (DVDs), which came onto the market in 1996, rely on red AlInGaP semiconductor lasers and have a data capacity of about 4.7 gigabytes (Gbytes), compared to 0.65 Gbytes for compact disks (CDs) which use infrared lasers. By moving to violet wavelengths using III- $V$ nitride-based semiconductors, the capacity could be increased to more than 15 Gbytes. The violet III-V nitride-based LDs could also improve the performance of laser printers and undersea optical communications. III-V nitride-based semiconductors have a direct band gap that is suitable for blue light-emitting devices. The band gap energy of aluminum gallium indium nitride $(\mathrm{AlGaInN})$ varies between 6.2 and $2.0 \mathrm{eV}$, depending on its composition, at room temperature (RT). Thus, by using these semiconductors, red to ultraviolet-emitting devices can be fabricated.

First breakthrough for III-V nitride-based semiconductors was a use of AlN $[1,2]$ or GaN $[3,4]$ nucleation layers for the GaN growth. Using these nucleation layers, it became possible to obtain high-quality GaN films with a mirror like flat surface, a low residual carrier concentration, a high mobility and a strong photoluminescence (PL) intensity. Second big breakthrough for III-V nitride-based LEDs and LDs was that $p$-type GaN was obtained and that the reason why $p$-type GaN had not been obtained was clarified. For the LEDs and LDs, $p-n$ junction is used to inject holes and electrons into the active layers from $p$-type layer and $n$-type layer. Thus; both $p$-type and $n$-type conductivity control must be required to fabricate those devices. It was easy to make $n$-type GaN from the beginning. However, it was impossible to obtain $p$-type GaN films for a long time $[5,6]$. Unavailability of $p$-type GaN films had prevented III-V nitrides from the realization of light-emitting devices, such as blue LEDs and LDs. Since 1970s, many people had tried to make $p$-type $\mathrm{GaN}$ by doping $\mathrm{Zn}$ [7], $\mathrm{Be}$ [8], $\mathrm{Mg}$ [9], $\mathrm{Cd}$ [10] and etc. into $\mathrm{GaN}$ as an acceptor impurity. However, unknown reason prevented from obtaining a low resistivity $p$-type GaN when they were doped into GaN. In 1989, Amano et al. [11] obtained the p-type GaN films using Mg-doping as an acceptor impurity and a post low-energy electron-beam irradiation (LEEBI) treatment by means of metal organic chemical vapor deposition (MOCVD) growth method. After the growth, LEEBI treatment was performed for Mg-doped GaN films to obtain a low-resistivity $p$-type GaN film. The effect of the LEEBI treatment was considered to be $\mathrm{Mg}$ displacement by the energy of the electron beam irradiation. In spite of this achievement of $p$-type GaN, nobody except for Amano et al. had succeeded in obtaining $p$-type GaN until 1992 because the mechanism of the LEEBI treatment was not understood exactly. In 1992, Nakamura et al. [12,13] obtained the $p$-type $\mathrm{GaN}$ films using post $\mathrm{N}_{2}$-ambient thermal annealing for $\mathrm{Mg}$-doped $\mathrm{GaN}$ instead of the LEEBI treatment. Before thermal annealing, the resistivity of $\mathrm{Mg}$-doped GaN films was approximately $1 \times 10^{6} \Omega \cdot \mathrm{cm}$. After thermal annealing at temperatures above $700^{\circ} \mathrm{C}$, the resistivity became $2 \Omega \cdot \mathrm{cm}$ [12]. Low-resistivity $p$-type GaN films, which were obtained by $\mathrm{N}_{2}$-ambient thermal annealing, showed a resistivity as high as $1 \times 10^{6} \Omega \cdot \mathrm{cm}$ after $\mathrm{NH}_{3}$-ambient thermal annealing at temperatures above $600^{\circ} \mathrm{C}$ [13]. Finally, they proposed that atomic hydrogen produced by $\mathrm{NH}_{3}$ dissociation at temperatures above $400^{\circ} \mathrm{C}$ was related to the acceptor compensation 
mechanism [13]. A hydrogenation process, whereby acceptor- $\mathrm{H}$ neutral complexes were formed in $p$-type GaN films, was proposed [13]. The formation of acceptor-H neutral complexes causes acceptor compensation. Now, this hydrogenation process has been accepted as the acceptor compensation mechanism of $p$-type III-V nitride-based semiconductor by many researchers [14-18]. Theoretical calculation of this hydrogen passivation was made by Neugebauer and Van De Walle [18]. Thus, in 1992, over 20 year's mystery of $p$-type GaN was resolved.

Third big breakthrough was that a. high quality InGaN film has become available. As mentioned above, an InGaN active layer is used for all of the III-V nitride-based LEDs and LDs to emit red to UV light. Thus, InGaN is the most important compound semiconductor among III-V nitride compounds because the InGaN active layer emits light by the recombination of the injected electrons and holes into the InGaN. In spite of this importance, nobody had succeeded in obtaining high quality InGaN films which could emit a strong band to band emission at RT by optical pumping or current injection [19-21]. In 1992, Nakamura and Mukai [22] succeeded in growing high quality InGaN films for the first time which emitted a strong band to band emission from green to UV by changing the In. content of InGaN using a novel two-flow MOCVD method. Finally, Nakamura et al. [23] grew InGaN multi-quantum-well (MQW) structure and confirmed an enhanced strong PL intensity from quantized energy levels of the InGaN well layer with a thickness of $25 \AA$. A small amount of indium added into the GaN is very important to obtain a strong band to band emission because GaN without the indium cannot emit a strong band to band emission at RT.

Using the above-mentioned major breakthrough techniques, in 1994, Nakamura et al. developed first blue InGaN/AIGaN double heterostructure LEDs [4, 24] and, then developed blue/green InGaN single-quantum-well (SQW) structure LEDs in $1995[4,25]$. Then, ultraviolet (UV)/amber LEDs [26, 27] and first demonstration of RT violet laser light emission in InGaN/GaN/AlGaN-based heterostructures under pulsed operations were achieved $[4,28]$. Since Nakamura et al,'s report of pulsed operation, many groups have reported the pulsed operation of the LDs using the same structure [29-35]. Then, the latest results showed that the lifetime became as long as 1000 [36] and 10000 hours [37] under RT continuous-wave (CW) operation. Also, high power LDs were fabricated using epitaxially lateral overgrown GaN (ELOG) [38] and GaN substrates [39]. All of these light-emitting devices use an InGaN active layer instead of a GaN active layer because it is difficult to fabricate a highly efficient light-emitting device using a GaN active layer, the reason for which is still not well known. Also, the InGaN active layer in these LEDs and LDs includes a large number of threading dislocations (TDs) from $1 \times 10^{8}$ to $1 \times 10^{12} \mathrm{~cm}^{-2}$ originating from the interface between $\mathrm{GaN}$ and the sapphire substrate due to a large lattice mismatch of $15 \%$ [40]. In spite of the large number of dislocations, the efficiency of the InGaN-based LEDs and LDs is much higher than that of the conventional III-V compound semiconductor (AIGaAs and AlInGaP)-based LEDs and LDs. Here, the recent performance of $\mathrm{UV} /$ blue/green/amber InGaN quantum-well (QW) structure LEDs and violet LD are described. 


\section{InGaN-based UV/blue/green/amber LEDs}

III-V nitride films were grown by the two-flow metalorganic chemical vapor deposition (MOCVD) method, details of which are described elsewhere [4]. The growth was conducted at atmospheric pressure. Sapphire with (0001) orientation (C-face), of two-inch diameter, was used as a substrate. The green LED device structures consist of a $300 \AA \mathrm{GaN}$ buffer layer grown at a low temperature $\left(550^{\circ} \mathrm{C}\right)$, a $4-\mu \mathrm{m}$-thick layer of $n$-type $\mathrm{GaN}: \mathrm{Si}$, a $30-\AA$-thick active layer of undoped $\mathrm{In}_{0.45} \mathrm{Ga}_{0.55} \mathrm{~N}$, a 1000 - $\AA$-thick layer of $p$-type $\mathrm{Al}_{0.2} \mathrm{Ga}_{0.8} \mathrm{~N}: \mathrm{Mg}$, and a 0.5 - $\mu \mathrm{m}$-thick layer of $p$-type GaN:Mg, as shown in Fig. 1. The active region forms a SQW structure consisting of a $30 \AA \mathrm{In}_{0.45} \mathrm{Ga}_{0.55} \mathrm{~N}$ well layer sandwiched by $4 \mu \mathrm{m} n$-type $\mathrm{GaN}$ and $1000 \AA$-type $\mathrm{Al}_{0.2} \mathrm{Ga}_{0.8} \mathrm{~N}$ barrier layers. The In composition of the InGaN well layer was changed to nearly zero for UV LEDs [26], 0.2 for blue LEDs [4, 25], and much higher for amber LEDs [27]. For UV LEDs, $\mathrm{Al}_{0.2} \mathrm{Ga}_{0.8} \mathrm{~N}$ barrier layer was used for both the $n$ - and $p$-type barrier layers. Fabrication of LED chips was started by partially etching the surface of the $p$-type GaN layer until the $n$-type GaN layer was exposed. Next, Ni/Au contact was evaporated onto the $p$-type GaN layer and a $\mathrm{Ti} / \mathrm{Al}$ contact onto the $n$-type GaN layer, as shown in Fig. 1 . The wafer was cut into rectangles $(350 \mu \mathrm{m} \times 350 \mu \mathrm{m})$. These chips were set on a lead frame, and were then molded. The characteristics of LEDs were measured under direct current (DC)-biased conditions at room temperature.

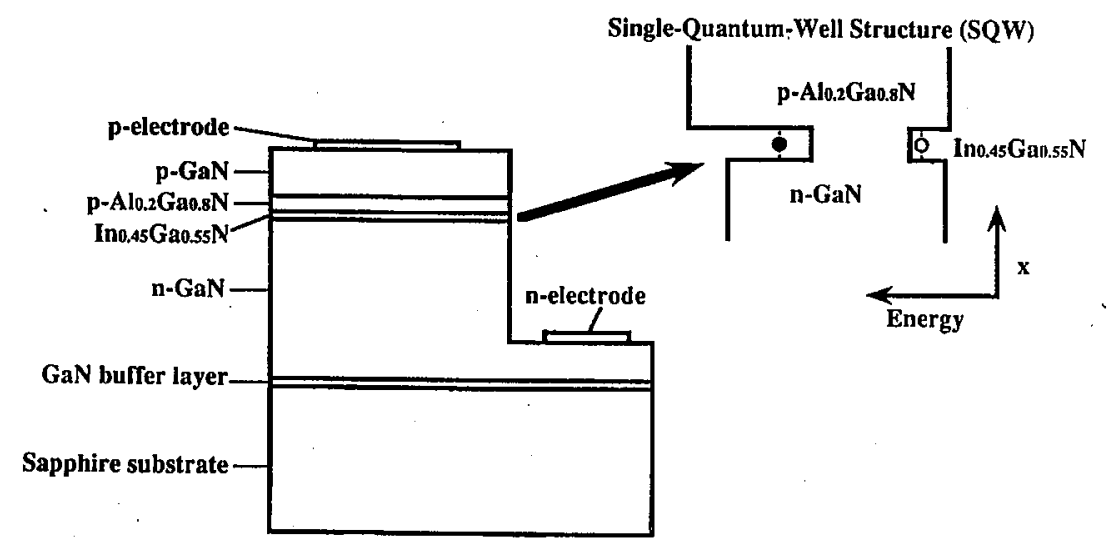

Fig. 1. The structure of green InGaN SQW LEDs.

Figure 2 shows the external quantum efficiency of those LEDs as a function of the emission wavelength. The typical external quantum efficiencies of the UV, blue, green and amber LEDs were $7.5 \%, 11.2 \%, 11.6 \%$, and $4.8 \%$, respectively. Figure 3 shows the luminous efficiencies of the LEDs as a function of the emission wavelength. The luminous efficiencies of blue and green LEDs were $5 \mathrm{~lm} / \mathrm{W}$ and $30 \mathrm{~lm} / \mathrm{W}$, respectively. For comparison, these of the red AlInGaP LEDs are around $20-30 \mathrm{~lm} / \mathrm{W}$. The luminous efficiency of the white conventional incandescent bulb lamp is around $10 \mathrm{~lm} / \mathrm{W}$, as shown in Fig. 3. By combining the blue, green and 

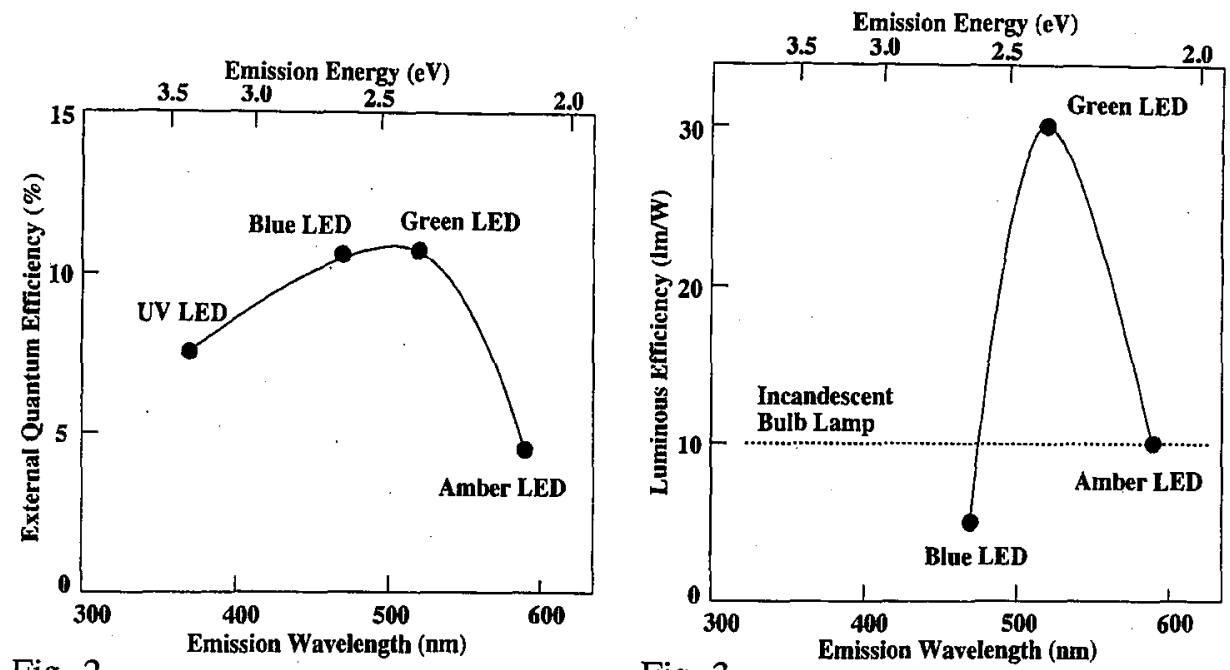

Fig. 2

Fig. 3

Fig. 2. The external quantum efficiencies of various InGaN-based LEDs as a function of the emission wavelength with a different In mole fraction in the active layer.

Fig. 3. The luminous efficiencies of various InGaN-based LEDs as a function of the emission wavelength with a different In mole fraction in the active layer.

red LEDs, we can fabricate white LEDs with a luminous efficiency of $30 \mathrm{~lm} / \mathrm{W}$ which is much higher than that of conventional incandescent bulb lamps. The lifetime of the LEDs is longer than 100000 hours which is much longer than that of the conventional incandescent bulb lamps. Thus, replacement of the conventional incadenscent bulb lamps with the InGaN-based blue, green LEDs and AlInGaP-based red LEDs could result in saving energy and resources. These InGaN-based blue and green LEDs are used for many applications such as LED full-color displays, LED traffic signal lights, lighting and etc.

Even for UV LEDs, the active layer was InGaN with a small amount of In, not the GaN active layer [26]. The output power of the UV LEDs containing a small amount of In in the active layer, with the emission wavelength of $371 \mathrm{~nm}$ was about 10 times higher than that containing no In with the emission wavelength of $368 \mathrm{~nm}$. Thus, high-power UV LEDs can be obtained only when using the InGaN active layer instead of the GaN active layer. This is probably related to the deep localized energy states which were caused by the In composition fluctuations of the InGaN active layer due to a phase separation during growth [41-44]. Chichibu et al. [41, 44] and Narukawa and co-workers [42, 43] observed a large Stokes shift between the absorption and emission energies of the InGaN quantum energy levels, using the photovoltage (PV) method, on the InGaN SQW LEDs and MQW structure LDs. They attributed the high efficiency of InGaN-based LEDs and LDs, in spite of a large number of dislocation densities of $1-10 \times 10^{10} / \mathrm{cm}^{2}$, to the deep localized energy states in the InGaN well layers which acted like quantum dot energy states. The localization induced by the In composition fluctuations seems to be a key role of the high efficiency of the InGaN-based LEDs. When the 
electrons and holes are injected into the InGaN active layer of the LEDs, these carriers are captured by the localized energy states before they are captured by the nonradiative recombination centers caused by the large number of TDs. It was reported that the TDs served as a nonradiative recombination center in GaN and InGaN [45-48]. These localized energy states can be formed only in InGaN films during the growth due to a phase separation of the InGaN [41-44]. Assuming that the lateral spacing of the effective band gap (potential) minimum determines the carrier diffusion length in InGaN, the diffusion length was estimated to be lesss than $60 \mathrm{~nm}$ from the spatially resolved cathodoluminescence (CL) spectrum mapping measurement [44]. Sugahara et al. [48] also concluded that the efficiency of light emission is high as long as the minority carrier diffusion length is shorter than the dislocation spacing. Considering about these previous results, the carrier diffusion length determined by the potential fluctuation due to the InGaN phase separation must be less than the dislocation spacing in the InGaN layer in order to obtain high-efficient InGaN-based LEDs. Without In in the active layer, there are no In composition fluctuations that form the deep localized energy state in the InGaN active layer. Thus, the quantum-confined Stark effects (QCSE) resulting from the piezoelectric field due to the strain becomes dominant. This field, if strong enough, will induce a spatial separation of the electron and hole wave functions in the well. As the charge density concentrates near the walls of the well, the wave function overlap decreases and the interband recombination rate reduces. Also, there is no In composition fluctuation where carriers are captured by the localized energy states before they are captured by the nonradiative recombination centers caused by the large number of TDs. Thus, the efficiency of the UV LEDs becomes extremely low when the active layer is GaN. Therefore, the InGaN active layer acts as a key role of III-V nitride-based highly efficient LEDs and LDs.

\section{InGaN-based violet LDs}

The improvement of the lifetime of the LDs was performed using new structures and substrates for the LDs. One of the problems for the LDs was that it was difficult to grow the thick AlGaN cladding layer required for optical confinement, due to the formation of cracks during growth. These cracks are due to the stress introduced in the AlGaN cladding layers caused by lattice mismatch, and the difference in thermal expansion coefficients between the AlGaN cladding layer and GaN layers. In the case of a thin AlGaN layer, the elastic strain is not relieved by the formation of cracks and dislocations, thus the crystal quality of the AlGaN cladding layer improves. Here, the InGaN MQW-structure LDs, which have GaN/AlGaN modulation doped strained-layer superlattice (MD-SLS) as cladding layers within the range of critical thickness instead of thick AlGaN layers are described. As a substrate, the epitaxially lateral overgrown GaN (ELOG) on sapphire was used to reduce the number of threading dislocations of the GaN epilayer.

Selective growth of GaN was performed on a 2- $\mu \mathrm{m}$-thick GaN layer grown on a (0001) C-face sapphire substrate under a low pressure of 100 torr [36-38]. The $2-\mu \mathrm{m}$-thick silicon dioxide $\left(\mathrm{SiO}_{2}\right)$ mask was patterned to form 3 - $\mu$ m-wide stripe windows with a periodicity of $13 \mu \mathrm{m}$ in the GaN $\langle 1-100\rangle$ direction. Following the 


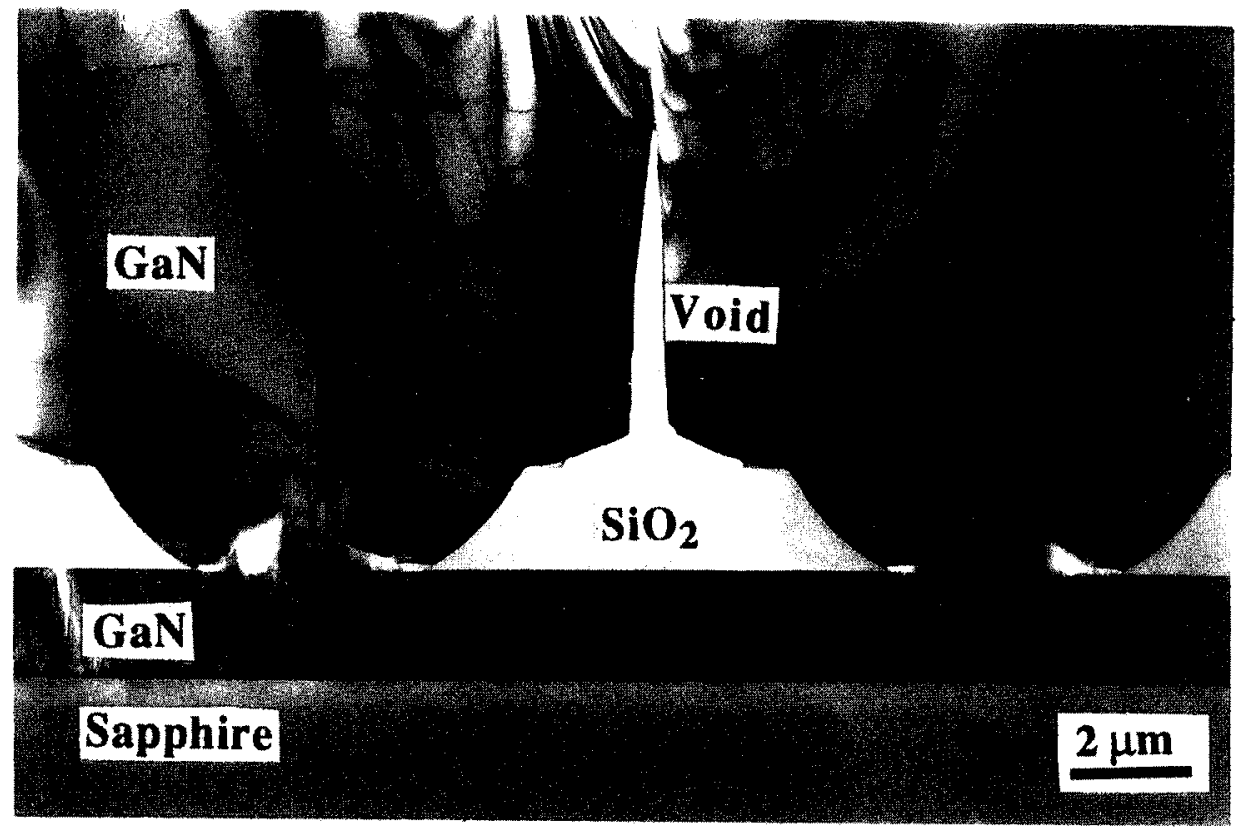

Fig. 4. Cross-sectional transmission electron micrographs (TEM) of the laterally overgrown $\mathrm{GaN}$ layer on a $\mathrm{SiO}_{2}$ mask and window area.

20- $\mu$ m-thick GaN growth on the $\mathrm{SiO}_{2}$ mask pattern, the coalescence of the selectively grown GaN enabled the achievement of a flat GaN surface over the entire substrate. This coalesced GaN was designated the ELOG [36-38]. Figure 4 shows thecross-sectional transmission electron microscopy (TEM) images of the ELOG substrate. Threading dislocations, originating from the GaN/sapphire interface, propagate to the regrown GaN layer within the window regions of the mask. Note that the dislocations extend to only just above the window areas. In contrast, there were no observable threading dislocations in the overgrown layer. However, very few short edge-on dislocation segments parallel to the interface plane were observed in the GaN layer on the $\mathrm{SiO}_{2}$ mask area. These dislocations were parallel to the $(0001)$ plane via the extension of the vertical threading dislocations after a $90^{\circ}$ bend in the regrown region. These dislocations did not subsequently propagate to the surface of the overgrown GaN layers. The defect density, as determined by plan-view TEM, above the $\mathrm{SiO}_{2}$ mask area was almost zero within the area of $10 \mu \mathrm{m} \times 10 \mu \mathrm{m}$, and that on the window area was approximately $1 \times 10^{7} / \mathrm{cm}^{2}$.

The InGaN MQW-structure LD was grown on the above-mentioned ELOG substrate. The InGaN MQW-structure LD consisted of a 3 - $\mu$ m-thick layer of $n$-type $\mathrm{GaN}: \mathrm{Si}$, a $0.1-\mu \mathrm{m}$-thick $n$-type $\mathrm{In}_{0.1} \mathrm{Ga}_{0.9} \mathrm{~N}: \mathrm{Si}$, a $\mathrm{Al}_{0.14} \mathrm{Ga}_{0.86} \mathrm{~N} / \mathrm{GaN}$ MD-SLS cladding layer consisting of 12025 - $\AA$-thick Si-doped GaN separated by 25- $\AA$-thick undoped $\mathrm{Al}_{0.14} \mathrm{Ga}_{0.86} \mathrm{~N}$ layers, a 0.1 - $\mu$ m-thick layer of Si-doped $\mathrm{GaN}$, an $\mathrm{In}_{0.15} \mathrm{Ga}_{0.85} \mathrm{~N} / \mathrm{In}_{0.02} \mathrm{Ga}_{0.98} \mathrm{~N} \mathrm{MQW}$ structure consisting of four 35 - $\AA$-thick Si-doped $\operatorname{In}_{0.15} \mathrm{Ga}_{0.85} \mathrm{~N}$ well layers forming a gain medium separated by 105 - $\AA$-thick Si-doped $\mathrm{In}_{0.02} \mathrm{Ga}_{0.98} \mathrm{~N}$ barrier layers, a 200 - $\AA$-thick layer of $p$-type $\mathrm{Al}_{0.2} \mathrm{Ga}_{0.8} \mathrm{~N}: \mathrm{Mg}$, 
a $0.1-\mu$ m-thick layer of Mg-doped GaN, a $\mathrm{Al}_{0.14} \mathrm{Ga}_{0.86} \mathrm{~N} / \mathrm{GaN}$ MD-SLS cladding layer consisting of 12025 - $\AA$-thick $\mathrm{Mg}$-doped GaN separated by $25-\AA$-thick undoped $\mathrm{Al}_{0.14} \mathrm{Ga}_{0.86} \mathrm{~N}$ layers and a $0.05-\mu$ m-thick layer of $p$-type $\mathrm{GaN}: \mathrm{Mg}$. The $0.1-\mu \mathrm{m}$-thick $n$-type and $p$-type GaN layers were light-guiding layers. The $n$-type and $p$-type $\mathrm{Al}_{0.14} \mathrm{Ga}_{0.86} \mathrm{~N} / \mathrm{GaN}$ MD-SLS layers acted as cladding layers for confinement of the carriers and the light emitted from the active region of the InGaN MQW structure. The 0.1- $\mu$ m-thick $n$-type $\operatorname{In}_{0.1} \mathrm{Ga}_{0.9} \mathrm{~N}$ served as a buffer layer for the thick AlGaN film growth to prevent cracking. The structure of the ridge-geometry InGaN MQW LD was almost the same as that described previously [4]. The LD structure grown on the ELOG substrate is shown schematically in Fig. 5. Next, the surface of the $p$-type GaN layer was partially etched until the

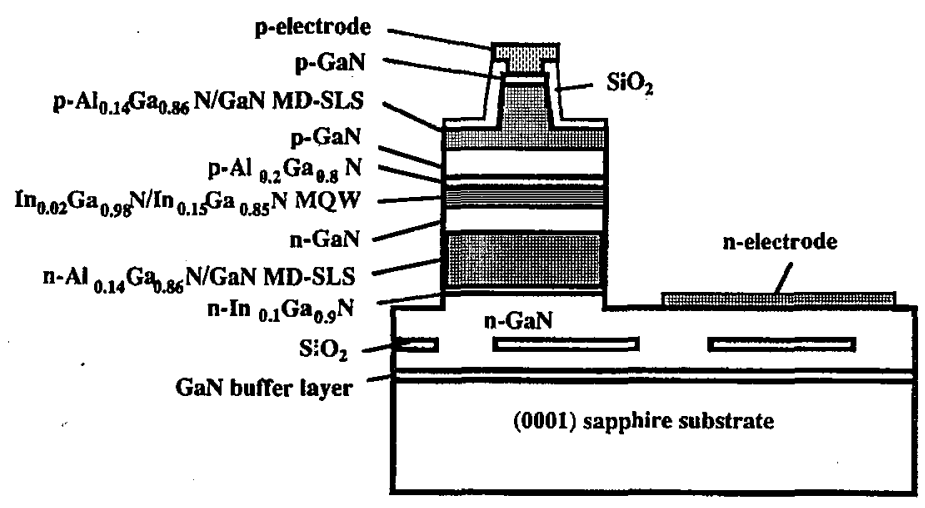

Fig. 5. The structure of the InGaN MQW-structure LDs with MD-SLS cladding layers grown on the ELOG substrate.

$n$-type $\mathrm{GaN}$ layer and the $p$-type $\mathrm{Al}_{0.14} \mathrm{Ga}_{0.86} \mathrm{~N} / \mathrm{GaN}$ MD-SLS cladding layer were exposed, to form a ridge-geometry LD [4]. The laser cavity was formed parallel to the direction of the $\mathrm{SiO}_{2}$ stripe. The ridge-geometry LDs were fabricated with an area of $4 \times 450 \mu \mathrm{m}$. A mirror facet was also formed by dry etching. High-reflection facet coatings (50\%) consisting of 2 pairs of quarter-wave $\mathrm{TiO}_{2} / \mathrm{SiO}_{2}$ dielectric multilayers were used to reduce the threshold current. A Ni/Au contact was evaporated onto the $p$-type $\mathrm{GaN}$ layer, and a $\mathrm{Ti} / \mathrm{Al}$ contact was evaporated onto the $n$-type GaN layer. The electrical characteristics of the LDs fabricated in this manner were measured under conditions of direct current (DC) at room temperature.

Figure 6 shows typical voltage-current (V-I) characteristics and the light output power per coated facet of the LD as a function of the forward DC current (L-I) at RT. This $\mathrm{LD}$ was fabricated on the $\mathrm{GaN}$ layer above the $\mathrm{SiO}_{2}$ mask region. When the $\mathrm{LD}$ was formed on the $\mathrm{GaN}$ layer above the $\mathrm{SiO}_{2}$ mask region without any dislocations, the threshold current was $48 \mathrm{~mA}$, which corresponded to a threshold current density of $2.7 \mathrm{kA} \mathrm{cm}^{-2}$. When the $\mathrm{LD}$ formed on the window region with the high TD density had a threshold current density of 4.5 to $9 \mathrm{kA} \mathrm{cm}^{-2}$, which was much higher than that of the $\mathrm{LD}$ formed on the $\mathrm{SiO}_{2}$ mask. The higher threshold current density is probably caused by the large number of 


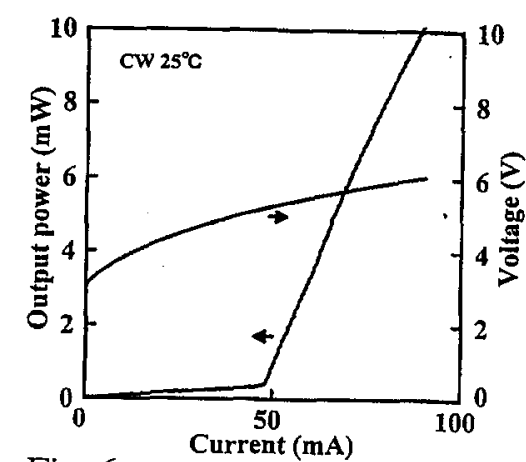

Fig. 6

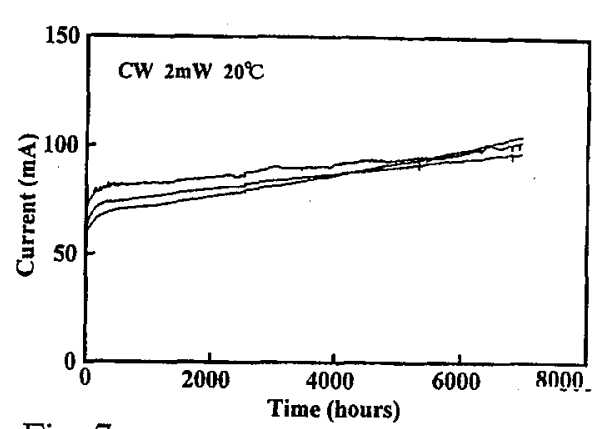

Fig. 7

Fig. 6. Typical L-I and V-I characteristics of InGaN MQW LDs measured under CW operation at RT.

Fig. 7. Operating current as a function of time under a constant output power of $2 \mathrm{~mW}$ per facet controlled using an autopower controller. The InGaN MQW LDs with MD-SLS cladding layers grown on the ELOG substrate were operated under DC at $20^{\circ} \mathrm{C}$.

TD density of $1 \times 10^{7} \mathrm{~cm}^{-2}$ at the window region. It was reported that the TD served as a diffusion pathway of metals, and did as a leakage current pathway in InGaN and GaN $[49,50]$. Thus, there is a possibility that a leakage current due to a large number of TDs caused the high threshold current density on the window region. Further studies are required to determine the reasons of the high threshold current density caused by TDs.

Figure 7 shows the results of a lifetime test for CW-operated LDs carried out at $20^{\circ} \mathrm{C}$, in which the operating current is shown as a function of time under a constant output power of $2 \mathrm{~mW}$ per facet controlled using an autopower controller (APC). These LDs were fabricated on the GaN layer above the $\mathrm{SiO}_{2}$ mask region. The initial threshold current density of these LDs were between 2.5 and $4.5 \mathrm{kA} / \mathrm{cm}^{2}$. After 7000 hours of operation, the operating current is still increasing gradually with increasing operating time. Based on the LDs still surviving after 7000 hours of operation, the lifetime of some of the LDs was estimated to be longer than 10000 hours from the degradation speed. The degradation speed was defined to be the derivatives of $\mathrm{d} I / \mathrm{d} t$ ( $\mathrm{mA} / 100$ hours), where $I$ is the operating current of the LDs and $t$ is the time. Using this degradation speed, the lifetime was estimated from the time when the operating current became twice of the initial operating current of the LDs. This long lifetime of the LDs is probably due to a low threshold current density resulting from a reduced number of TD density of the $\mathrm{GaN}$ layer above the $\mathrm{SiO}_{2}$ mask region.

The emission spectra of the LDs were measured under RT CW operation at currents of 50 and $60 \mathrm{~mA}$, as shown in Fig. 8. An optical spectrum analyzer was used to measure the spectra of the LDs with a resolution of $0.001 \mathrm{~nm}$. At a current of $50 \mathrm{~mA}$, longitudinal modes with a mode separation of $0.04 \mathrm{~nm}$ due to the cavity were observed. At a current of $60 \mathrm{~mA}$, a single-mode emission was observed at an emission wavelength of $396.6 \mathrm{~nm}$. 


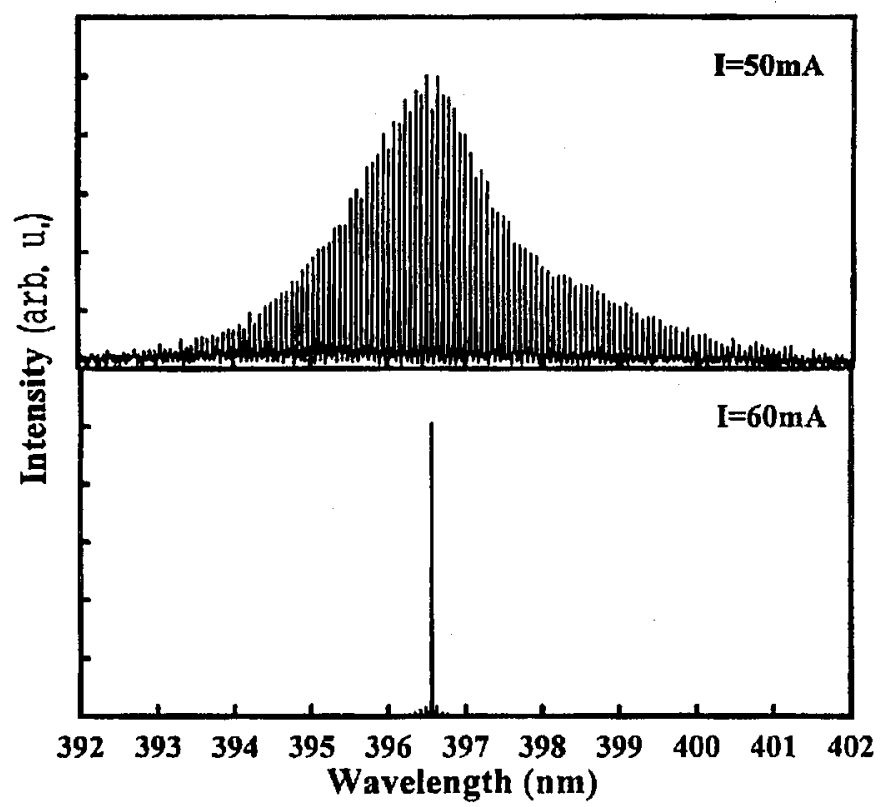

Fig. 8. Laser emission spectra measured under RT CW operation with currents of $50 \mathrm{~mA}$ and $60 \mathrm{~mA}$.

In summary, InGaN MQW LDs with the MD-SLS cladding layers grown on the ELOG substrate were demonstrated to have an estimated lifetime of more than 10000 hours under RT CW operation. These results suggest an imminent commercialization of the III-V nitride-based short-wavelength LDs. The TD increased the threshold current density of the LDs. Considering this behavior of TDs, free standing GaN substrate, which is made by growing the thick ELOG $(200 \mu \mathrm{m})$ and, then, removing the sapphire, would be a promising substrate due to a lack of a large size of bulk GaN substrate $[39,51]$.

\section{References}

[1] S. Yoshida, S. Misawa, S. Gonda, Appl. Phys. Lett. 42, 427 (1983).

[2] H. Amano, N. Sawaki, I. Akasaki, T. Toyoda, Appl. Phys. Lett. 48, 353 (1986).

[3] S. Nakamura, G. Fasol, The Blue Laser Diode, 1st ed., Springer-Verlag, Heidelberg 1997.

[4] S. Nakamura, Jpn. J. Appl. Phys. 30, L1705 (1991).

[5] S. Strite, H. Morkoç, J. Vac. Sci. Technol. B 10, 1237 (1992).

[6] F.A. Ponce, D.P. Bour, Nature 386, 351 (1997).

[7] J.I. Pankove, E.A. Miller; J.E. Berkeyheiser, RCA Review 32, 383 (1971).

[8] J.I. Pankove, M.T. Duffy, E.A. Miller, J.E. Berkeyheiser, J. Luminesc. 8, 89 (1973).

[9] H.P. Maruska, W.C. Rhines, D.A. Stevenson, Mat. Res. Bull. 7, 777 (1972).

[10] O. Lagerstedt, B. Monemar, J. Appl. Phys. 45, 2266 (1974). 
[11] H. Amano, M. Kito, K. Hiramatsu, I. Akasaki, Jpn. J. Appl. Phys. 28, L2112 (1989).

[12] S. Nakamura, T. Mukai, M. Senoh, N. Iwasa, Jpn. J. Appl. Phys. 31, L139 (1992).

[13] S. Nakamura, N. Iwasa, M. Senoh, T. Mukai, Jpn. J. Appl. Phys. 31, 1258 (1992).

[14] C. Wang, R.F. Davis, Appl. Phys. Lett. 63, 990 (1993).

[15] M. Rubin, N. Newman, J.S. Chan, T.C. Fu, J.T. Ross, Appl. Phys. Lett. 64, 64 (1994).

[16] M.S. Brandt, N.M. Johnson, R.J. Molnar, R. Singh, T.D. Moustakas, Appl. Phys. Lett. 64, 2264 (1994).

[17] J.M. Zavada, R.G. Wilson, C.R. Abernathy, S.J. Pearton, Appl. Phys, Lett. 64, 2724 (1994).

[18] J. Neugebauer, C. Van De Walle, Phys. Rev. B 50, 8067 (1994).

[19] T. Nagatomo, T. Kuboyama, H. Minamino, O. Omoto, Jpn. J. Appl. Phys. 28, L1334 (1989).

[20] T. Matsuoka, H. Tanaka, T. Sasaki, A. Katsui, Inst. Phys. Conf. Ser. 106, 141 (1990).

[21] T. Matsuoka, J. Cryst. Growth 124, 433 (1992).

[22] S. Nakamura, T. Mukai, Jpn. J. Appl. Phys. 31, L1457 (1992).

[23] S. Nakamura, T. Mukai, M. Senoh, S. Nagahama, N. Iwasa, J. Appl. Phys. 74, 3911 (1993).

[24] S. Nakamura, T. Mukai, M. Senoh, Appl. Phys. Lett. 64, 1687 (1994).

[25] S. Nakamura, M. Senoh, N. Iwasa, S. Nagahama, T. Yamada, T. Mukai, Jpn. J. Appl. Phys. 34, L1332 (1995).

[26] T. Mukai, D. Morita, S. Nakamura, J. Cryst. Growth 189/190, 778 (1998).

[27] T. Mukai, H. Narimatsu, S. Nakamura, Jpn. J. Appl. Phys. 37, L479 (1998).

[28] S. Nakamura, M. Senoh, S. Nagahama, N. Iwasa, T. Yamada, T. Matsushita, H. Kiyoku, Y. Sugimoto, Jpn. J. Appl. Phys. 35, L74 (1996).

[29] K. Itaya, M. Onomura, J. Nishino, L. Sugiura, S. Saito, M. Suzuki, J. Rennie, S. Nunoue, M. Yamamoto, H. Fujimoto, Y. Kokubun, Y. Ohba, G. Hatakoshi, M. Ishikawa, Jpn. J. Appl. Phys. 35, L1315 (1996).

[30] G.E. Bulman, K. Doverspike, S.T. Sheppard, T.W. Weeks, H.S. Kong, H.M. Dieringer, J.A. Edmond, J.D. Brown, J.T. Swindell, J.F. Schetzena, Electron. Lett. 33, 1556 (1997).

[31] M.P. Mack, A. Abare, M. Aizcorbe, P. Kozodoy, S. Keller, U.K. Mishra, L. Coldren, S. DenBaars, MRS Internet J. Nitride Semicond. Res. 2, 41 (1997) (a vailable from http:/nsr.mij.mrs.org/2/41/).

[32] A. Kuramata, K. Domen, R. Soejima, K. Horino, S. Kubota, T. Tanahashi, Jpn J. Appl. Phys. 36, L1130 (1997).

[33] F. Nakamura, T. Kobayashi, T. Asatsuma, K. Funato, K. Yanashima, S. Hashimoto, K. Naganuma, S. Tomioka, T. Miyajima, E. Morita, H. Kawai, M. Ikeda, J. Cryst. Growth 189/190, 841 (1998).

[34] M. Kneissl, D.P. Bour, N.M. Johnson, L.T. Romano, B.S. Krusor, R. Donaldson, J. Walker, C.D. Dunnrowicz, Appl. Phys. Lett. $\vee 2,1539$ (1998).

[35] H. Katoh, T. Takeuchi, C. Anbe, R. Mizumoto, S. Yamaguchi, C. Wetzel, H. Amano, I. Akasaki, Y. Kaneko, N. Yamada, Jpn. J. Appl. Phys. 37, L444 (1998). 
[36] S. Nakamura, M. Senoh, S. Nagahama, N. Iwasa, T. Yamada, T. Matsushita, H. Kiyoku, Y. Sugimoto, T. Kozaki, H. Umemoto, M. Sano, K. Chocho, Appl. Phys. Lett. 72, 211 (1998).

[37] S. Nakamura, M. Senoh, S. Nagahama, N. Iwasa, T. Yamada, T. Matsushita, H. Kiyoku, Y. Sugimoto, T. Kozaki, H. Umemoto, M. Sano, K. Chocho, Jpn. J. Appl. Phys. 36, L1568 (1997).

[38] S. Nakamura, M. Senoh, S. Nagahama, N. Iwasa, T. Yamada, T. Matsushita, H. Kiyoku, Y. Sugimoto, T. Kozaki, H. Umemoto, M. Sano, K. Chocho, Jpn. J. Appl. Phys. 37, L627 (1998).

[39] S. Nakamura, M. Senoh, S. Nagahama, N. Iwasa, T. Yamada, T. Matsushita, H. Kiyoku, Y. Sugimoto, T. Kozaki, H. Umemoto, M. Sano, K. Chocho, Jpn. J. Appl. Phys. 37, L309 (1998).

[40] S.D. Lester, F.A. Ponce, M.G. Craford, D.A. Steigerwald, Appl. Phys. Lett. 66, 1249 (1995).

[41] S. Chichibu, T. Azuhata, T. Sota, S. Nakamura, Appl. Phys. Lett. 69, 4188 (1996).

[42] Y. Narukawa, Y. Kawakami, Sz. Fujita, Sg. Fujita, S. Nakamura, Phys. Rev. B 55, 1938 (1997).

[43] Y. Narukawa, Y. Kawakami, M. Funato, Sz. Fujita, Sg. Fujita, S. Nakamura, Appl. Phys. Lett. 70, 981 (1997).

[44] S. Chichibu, K. Wada, S. Nakamura, Appl. Phys. Lett. 71, 2346 (1997).

[45] X.H. Wu, C.R. Elsass, A. Abare, M. Mack, S. Keller, P.M. Petroff, S.P. Denbaars, J.S. Speck, S.J. Rosner, Appl. Phys. Lett. 72, 692 (1998).

[46] S. Keller, U.K. Mishra, S.P. Denbaars, W. Seifert, Jpn. J. Appl. Phys. 37, L431 (1998).

[47] S.J. Rosner, E.C. Carr, M.J. Ludowise, G. Girolami, H.I. Erikson, Appl. Phys. Lett. 70, 420 (1997).

[48] T. Sugahara, H. Sato, M. Hao, Y. Naoi, S. Kurai, S. Tottori, K. Yamashita, K. Nishino, L.T. Romano, S. Sakai, Jpn. J. Appl. Phys. 37, L398 (1998).

[49] C. Sasaoka, H. Sunakawa, A. Kimura, M. Nido, A. Usui, A. Sakai, J. Cryst. Growth 189/190, 61 (1998).

[50] A. Osinsky, S. Gangopadhyay, R. Gaska, B. Williams, M.A. Khan, D. Kuksenkov, H. Temkin, Appl. Phys. Lett. 71, 2334 (1997).

[51] S. Porowski, J. Cryst. Growth 189/190, 153 (1998). 